\title{
ОТ РЕДАКЦИИ
}

В сентябре 2019 г. мы получили следующее письмо:

«Уважаемый Олег Викторович [Никитин]! Постараюсь Вам что-то написать... Посланное Вам письмо [Н. А. Кондрашова. - Ред.] доказывает, иллюстрирует удивительное (для меня сейчас потрясающее!!!) отношение Николая Андреевича к настоящим и бывшим аспирантам МОПИ. Каждому из нас он казался отияом родным, на которого можно переложить собственные заботы, и он будет помогать нам обязательно. Причём каждому из нас казалось, что именно меня (его) он особенно иеент и выделяет из всей массы своих учеников. Это я позже поняла, что все мы так считали. До кониа своих дней со мной он переписывался. Я емудокладывала о своём научном росте, проблемах в работе, и он всегда и во всём помогал всем, чем мог.

Я бесконечно благодарна своему учителю и наставнику.

С уважением,

Г. М. Шипицььна».

Редакция сердечно благодарит профессора Г. М. Шипицыну за отклик на наше предложение написать воспоминания о Н. А. Кондрашове и такой ценный подарок. Фрагмент этого письма вместе с конвертом мы публикуем как память о замечательном человеке, сподвижнике, воспитателе и друге своих многочисленных учеников.

УДК $82-94$

DOI: $10.18384 / 2310-7278-2019-5-300-305$

\section{ЭПизоды...}

\section{Шипицына Г. М.}

Белгородский государственный национальный исследовательский университет 308015, г. Белгород, ул. Победы, д. 85, Российская Федерация

Аннотация. В «эпизодах» воссоздана эпоха конца 1960-1970-х гг.: учёба в аспирантуре, филологическое взросление, выбор темы диссертации и др. В диалогах и подлинных репликах показана атмоссрера общения с научным руководителем профрессором Н. А. Кондрашовым. Автор вспоминает необычные случаи из своей научной биографии, с юмором и живой лирической интонацией описывает эпизоды знакомства и последующего сотрудничества с учителем, отмечает самые яркие и запоминающиеся черты его характера и духовного облика.

Ключевые слова: история науки, филология, аспирантура, лингвистический портрет, словесная культура

\section{EPISODES...}

\section{G. Shipitsyna}

Belgorod State National Research University

85 ulitsa Pobedy, Belgorod 308015, Russian Federation

Abstract. The era of the late 1960s-1970s is reconstructed: studies in graduate school, linguistic maturity, the choice of thesis topics, etc. The atmosphere of communication with the supervisor Professor N. Kondrashov is shown in the dialogues and authentic replicas. The author recalls unusual cases from his scientific biography, with humor and lively lyrical intonation describes the episodes of acquaintance and subsequent cooperation with the teacher, notes the most vivid and memorable features of his character and spiritual appearance.

Keywords: history of science, philology, post-graduate course, linguistic portrait, language culture 
Николай Андреевич всегда говорил с любым человеком прямо, без дипломатических ухищрений, не был озабочен соблюдением норм изящного этикета и т. п.

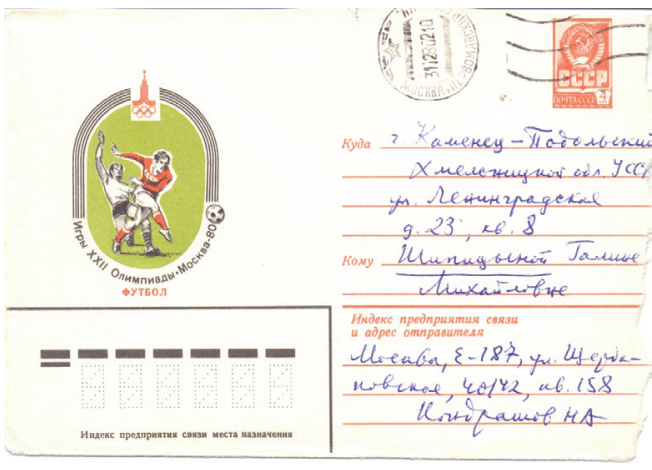

Конверт со штемпелем отправки 31.12.1980 г. Автограф Н. А. Кондрашова

Его прямолинейности и острого слова многие опасались (ср.: [4]). Я вспоминаю несколько эпизодов, связанных со мной лично.

\section{Эпизод первъцй. Знакомство}

1969-й год. Н. А. Кондрашов читал лекции на ФПК при МГПИ имени В. И. Ленина. На перемене я и другие молодые слушатели (ассистенты разных вузов без учёных степеней) подошли к нему, чтобы спросить о возможности поступить в аспирантуру к нему. Его ответ:

- Поступайте. Но в МОПИ имени Н. К. Крупской, мы в этом году будем набирать аспирантов.

Затем последовал мой робкий голос:

- Я бы тоже хотела к Вам поступить. Но меня вряд ли Вы возьмёте, посчитаете ненадёжным аспирантом: у меня в Свердловске муж и маленький ребёнок двух лет.

Н. А. Кондрашов тут же парировал и со свойственной ему иронией посмотрел на меня:

- А я вот таких именно и стараюсь брать.

Мы были удивлены такому повороту. Я и особенно другие «эфпэкашники» решились поинтересоваться у лектора:

- Почему?
Николай Андреевич (громко, обращаясь ко всем нам):

- А незамужние да без детей аспирантки в библиотеке не сидят и диссертации не пишут, а шляются по городу где попало в поисках мужей с московской пропиской. От них в науке толку мало.

Наши незамужние здесь же вывод на будущее для себя сделали, как им в аспирантуре себя вести...

\section{Эпизод второй. Выєбор темь диссертации}

\section{Н. А. Кондрашов:}

- Ну что, Шипицына, я тебе три дня давал. Придумала тему диссертации?

- Придумала, Николай Андреевич. Я буду определять системные связи в группе прилагательных, характеризующих человека.

Н. А. Кондрашов:

- Каких это, к примеру?

- Имеющих антонимы, типа умный глупьй, толстый - тонкий. И одиночные, типа седой, лысыьй, косой, хромой...

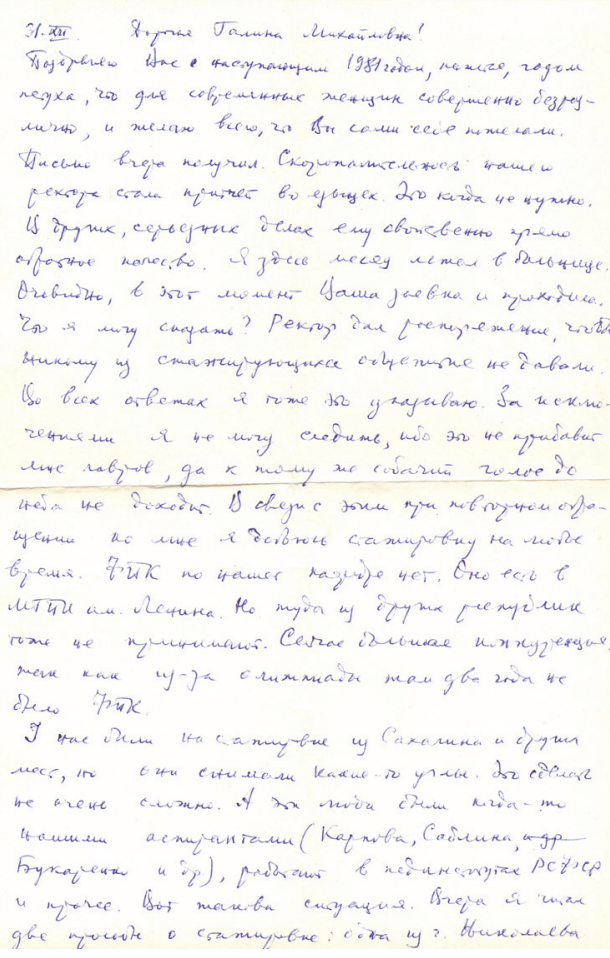

Письмо Н. А. Кондрашова Г. М. Шипицыной. Фрагмент. Автограф. Москва, 31 декабря 1980 г. 
В эту минуту в кабинет зашёл мужчина, преподаватель другой кафедры. Точно не помню, кто это был, вполне возможно, что профессор А. В. Дудников. Но слово хромой он слышал.

Н. А. Кондрашов ему:

- Смотри, какая девица ко мне поступила! Вот собирается в диссертации всего меня описать словами старый, дурной, кривой, плешивыци, лопоухий, кривононогий и т. п. Вот она сидит и уговаривает меня, чтобы ещё я срочно охромел: у неё, видите ли, без слова хромой мой портрет неполный, и её система не просматривается.

Оба смеются.

Вошедший преподаватель:

- Весело тут у вас. Ладно, я позже к тебе зайду.

\section{Эпизод третий. На кафедре}

Разговор на кафедре в перерыве между занятиями (парами) в присутствии несколько преподавателей, ожидающих конца перемены.

Н. А. Кондрашов:

- Шипицына, ты опять в Свердловск моталась? Нельзя пропускать заседаний кафедры! Кстати, я давал тебе два месяца на первую главу. Ты её написала?

Немного осмелев, и я вступила в словесную борьбу:

- Написала, Николай Андреевич. И приносила Вам показать. Вас самого-то не было. Куда-то Вы уезжали?!!

Н. А Кондрашов:

- Да, ездил к буржуям недобитым. В Чехословакию. Лекции там читал по истории словацкого языка.

- И что же больше всего Вам там понравилось? Красавица Прага?

- Н. А. Кондрашов (оглядывая присутствующих, с интонацией горделивого хвастовства):

- Да нет, Прагу я и раньше видел. Больше всего мне понравилось, что на почте у них, пока я там что-то спрашивал, писал и отправлял телеграмму в Москву, меня трижды обозвали словацкой свиньёй!

Все засмеялись.
Г. М. Шипицына:

- И что же в этом может нравиться? спросила я, недоумевая.

И получила в ответ типичное кондрашовское:

- А ты подумай на досуге, если ты лингвист.

Я тогда не поняла, причем тут «лингвист»... А позже подумала, ведь Николай Андреевич мог радоваться тому, что не забыл словацкий язык и владеет им так хорошо, что чехи приняли его за словака... Или по-чешски он говорил со словацким акцентом, что ещё лучше для него...

\section{Эпизод четвёртьй. $0 x$, уж эти бумаги!..}

У Николая Андреевича (он тогда был заведующим кафедрой и председателем диссовета) один из дней недели был присутственным. Все, кому он нужен был, поджидали его, в их числе была и я.

Он пришёл. Говорит:

- Шипицына, заходи первой.

Я последовала за ним в кабинет.

Н. А. Кондрашов:

- Садись вон там в углу. На тебе эти листы. Это будет автореферат одной дурёхи. Проверь его. Увидишь бред сивой кобылы, напиши на полях и можно на обратной стороне листа, проведи стрелочку от нужного места автореферата к тому, что напишешь, вот так. Поняла? И отдашь эти листы аспирантке такой-то, пусть ещё над ним поработает.

Я села, читаю, невольно наблюдая за происходящим.

Н. А. Кондрашов выглянул за дверь и кричит:

- Подписываю!!! Подписываю!!!

Стали заходить по одному (и не по одному сразу) люди, в том числе некоторые сотрудники факультета, подавали ему бумаги. Он смотрел на документ недолго и тут же его подписывал. Довольно быстро эта процедура закончилась. Я удивилась и говорю ему:

- Как же Вы, Николай Андреевич, не читая вдумчиво, всё подписывали! А вдруг в этих бумагах что-то не так? 
Н. А. Кондрашов (вполне серьёзно):

- Видишь ли, Галина, половину этих бумаг вообще никто и никогда читать не будет. Их и писать-то сразу не надо было, они вообще никому не нужны, но такой порядок в институтах у нас заведён. От них надо просто избавляться и всё. Зачем время тратить зря?! Когда ты будешь заведовать кафедрой, так же и делай. Важные документы люди тщательно готовят, прежде чем на подпись подавать, и я своим людям доверяю.

Г. М. Шипицына:

- А если в важных бумагах эти люди что-то неправильно написали, а Ваша подпись стоит на них?

Н. А. Кондрашов:

- Ну и что, поправят, если им это надо будет, снова могу подписать. Но пока никто меня не подводил. Важные бумаги - это те, которые пойдут в ВАК, но их учёный секретарь тщательно проверяет - это её хлеб. В министерство же бумаги посылает не завкафедрой, а ректор. Его секретари и пусть в них вчитываются. В принципе нужно понимать, что за документ и куда он пойдёт после твоей подписи, а не тратить время на чтение разных ненужных бумаг.

\section{Эпизод пятьй. Защита диссертащии}

1972-й год. Заседание диссертационного совета в МОПИ. Идёт защита моей кандидатской работы «Структура семемы качественного прилагательного и методы выделения её компонентов» [5]. Заседание ведёт, кажется, П.А. Лекант, а Николай Андреевич как научный руководитель скромно сидит в зале за партой вместе с заведующим кафедрой методики преподавания русского языка и литературы профессором А. В. Дудниковым. После моих ответов (излишне категоричных, может быть даже резковатых) оппоненту Дмитрию Николаевичу Шмелёву наступила тишина. Пауза. Для меня довольно тревожная. В это время сосед Н. А. Кондрашова по парте заведующий кафедрой методики что-то тихонько ска- зал Николаю Андреевичу. Тот же громко, на весь зал, ему отвечает:

- А ты что же думал, что у меня тоже одни дураки учатся?!!

В зале смешок, обстановка разрядилась.

В итоге все проголосовали «за».

\section{Эпизод иестой. Потом..}

После защиты кандидатской прощаюсь с Николаем Андреевичем перед отъездом.

$\mathrm{OH}$ :

- Через пять лет приедешь сюда со своей докторской диссертацией. А пока статьи пиши по близкой тебе, но новой теме, публикуй их в центральных издательствах. Я:

- Что Вы, Николай Андреевич, да разве я смогу?!! Вряд ли... Да за пять лет ещё, ну хоть бы попозже ...

Он:

- Попозже нельзя! Вот диабет меня замучил. Умереть могу. Кто тебе, дурочке такой, тогда поможет?!!

\section{Эпизод седьмой. Путешествие к книгам}

Мы, аспиранты Н. А. Кондрашова, иногда работали вместе с ним у него дома, на Щербаковской, недалеко от метро «Семёновская», в просторном кабинете профессора - помогали готовить к сдаче в издательство рукопись его будущей книги. А в перерывах отдыхали, общались... В один из таких моментов Николай Андреевич показывал нам свою библиотеку - несколько старых шкафов от пола до потолка, большая часть которых была заполнена книгами и научными журналами по славистике, трудами учёных классического русского и зарубежного языкознания. Некоторые из них на языках разных славянских народов, особенно много работ на чешском.

Потом он достал нам свою докторскую диссертацию [1]. Помню, что мы удивились её внешнему виду - она была огромной, в очень большой, специально изготовленной для этой рукописи папке. Я попробовала её подержать - она казалась мне довольно тяжёлой. 
Я спросила:

- А почему она такая огромная?

Н.А. Кондрашов:

- В то время не было установлено ограничений объёма диссертаций. Это вам теперь хорошо - не более 150 страниц на кандидатскую! А в моё время диссертации были длинными, а уж докторские ... - чем она больше, тем казалась основательней.

Он потом ещё стал рассуждать примерно так:

- Но ведь и действительно, в объёмный труд можно было вложить куда больше и материала, и идей. Потому и учёные старшего поколения - это настоящие исследователи языка, а не скороспелые кандидатишки (это слово я хорошо помню!) наук, как сейчас.

Мы также посмотрели его книги, поговорили об их проблематике.

Н. А. Кондрашов с горечью заметил:

- Да, всё это так... Книги мои далеко не для всех. Плохо, что у меня нет в семье такого наследника, кому бы я мог собранные в течение жизни книги, журналы и рукописи передать. Публике они неинтересны, только специалисту по славистике.

Кто-то из нас предложил завещать всё это институтской библиотеке.

Н. А. Кондрашов:

- В учебных библиотеках периодически проводится чистка - уничтожают всё, что не востребовано. В библиотеке место на полках надо для новейших учебников. Со временем всё это моё хозяйство пропадёт, уже сейчас мало кто интересуется историей языков. Наука стала массовой и по качеству иной - поверхностной. А чем дальше, тем ещё меньше будет людей, которых интересуют такие книги.
Я часто вспоминаю наш с Н. А. Кондрашовым разговор, глядя на современных студентов, которых трудно оторвать от их смартфонов. Они постоянно что-то там пишут, читают... Это стало главным в их жизни. Смартфоны заменяют им и книги, и людей.

\section{Эпизод последний. Смелее иди вперёд}

В то время на машинках печатали рукописи. После машинистки мы вычитывали у Н. А. Кондрашова дома за большим столом экземпляры книги (кажется, «Общее языкознание» [2; 3]). Это были - я, Толик Судариков, Венера Урманцева (его аспиранты из Башкирии) и кто-то ещё. Все читали одну и ту же страницу (она была в пяти экземплярах). Буковки исправляли так: наклеивали на ошибочную правильную. Ювелирная работа! По-моему, не один день мы трудились бригадой вместе с Николаем Андреевичем. Затем он мне прислал уже напечатанный учебник с надписью: «В благодарность за помощь в создании этой книги» (что-то в этом роде). Но мне её кто-то из аспирантов не вернул (как и многие другие книги). Аспирантам вообще не свойственно возвращать книги!

Потом, когда я уже стала кандидатом наук, мы с Николаем Андреевичем в соавторстве опубликовали две большие статьи. И он сказал:

- Дальше издавай одна, в соавторстве на докторскую не пройдёт. Ты и сама отлично их сделаешь, что ты всё боишься чего-то?! Смелее иди вперёд!!!

Статья поступила в редакцию 13.11.2019 2.

\section{ЛИТЕРАТУРА}

1. Кондрашов Н. А. Возникновение и начальный этап развития словацкого литературного языка: автореф. дисс. ... докт. филол. наук. М: МОПИ имени Н. К. Крупской, 1968. 46 с.

2. Кондрашов Н. А. Общее языкознание: (курс лекций). Ч. І. История языкознания. М.: МОПИ имени Н. К. Крупской, 1972. 173 с.

3. Кондрашов Н. А. Общее языкознание: (курс лекций). Ч. ІІ. Проблемы языкознания и методы изучения языка. М.: МОПИ имени Н. К. Крупской, 1974. 171 с.

4. Никитин О. В. Филолог-славист Н. А. Кондрашов как историограф науки и педагог (К 100-летию со дня рождения) // Русский язык в школе. 2019. № 5. С. 81-89.

5. Шипицына Г. М. Структура семемы качественного прилагательного и методы выделения её компонентов: дисс. ... канд. филол. наук. М.: МОПИ имени Н. К. Крупской. 1972. 229 с. 


\section{REFERENCES}

1. Kondrashov N. A. Vozniknovenie i nachal'nyi etap razvitiya slovatskogo literaturnogo yazyka: avtoref. diss. ... dokt. filol. nauk [Appearance and initial stage of development of the Slovak literary language: abstract of D. thesis in Philological Sciences]. Moscow, Moscow Region Pedagogical Institute named aftter N. K. Krupskaya, 1968. 46 p.

2. Kondrashov N. A. Obshchee yazykoznanie: (kurs lektsii). Ch. I. Istoriya yazykoznaniya [General linguistics: (course of lectures). Part I. The History of linguistics]. Moscow, Krupskaya Moscow Region Pedagogical Institute Publ., 1972. 173 p.

3. Kondrashov N. A. Obshchee yazykoznanie: (kurs lektsii). Ch. II. Problemy yazykoznaniya i metody izucheniya yazyka [General linguistics: (course of lectures). Part II. Problems of linguistics and methods of language learning]. Moscow, Krupskaya Moscow Region Pedagogical Institute Publ., 1974. 171 p.

4. Nikitin O. V. [Slavic philologist N. Kondrashov as a historiographer of science and a teacher (to his 100th anniversary)]. In: Russkii yazyk v shkole [Russian language at school], 2019, vol. 80, no. 5, pp. 81-89.

5. Shipitsyna G. M. Struktura sememy kachestvennogo prilagatel'nogo i metody vydeleniya ee komponentov: diss. ... kand. filol. nauk [The structure of sememe of qualitative adjective and methods of selection of its components: PhD thesis in Philological Sciences]. Moscow, Krupskaya Moscow Region Pedagogical Institute, $1972.229 \mathrm{p}$.

\section{ИНФОРМАЦИЯ ОБ АВТОРЕ}

Шипицына Галина Михайловна - доктор филологических наук, профессор кафедры русского языка и литературы Белгородского государственного национального исследовательского университета; e-mail: shipitsina@bsu.edu.ru

\section{AUTHOR INFORMATION}

Galina M. Shipitsyna - Doctor of Philological Sciences, Professor at the Department of Russian Language and Literature, Belgorod State National Research University; e-mail: shipitsina@bsu.edu.ru

\section{ПРАВИЛЬНАЯ ССЫЛКА НА СТАТЬЮ}

Шипицына Г. М. Эпизоды... // Вестник Московского государственного областного университета. Серия: Русская филология. 2019. № 5. С. 300-305.

DOI: $10.18384 / 2310-7278-2019-5-300-305$

\section{FOR CITATION}

Shipitsyna G. M. Episodes... . In: Bulletin of Moscow Region State University. Series: Russian philology, 2019, no. 5. pp. .300-305.

DOI: $10.18384 / 2310-7278-2019-5-300-305$ 